\title{
A Study on Structural, Optical, Electrical and Etching Characteristics of Pure and L-Alanine Doped Potassium Dihydrogen Phosphate Crystals
}

\author{
Ferdousi Akhtar, Jiban Podder* \\ Department of Physics, Bangladesh University of Engineering and Technology, Dhaka, Bangladesh. \\ Email: ${ }^{*}$ jpodder@phy.buet.ac.bd
}

Received August 27 $7^{\text {th }}, 2011$; revised October $1^{\text {st }}, 2011$; accepted October $9^{\text {th }}, 2011$.

\begin{abstract}
Pure potassium dihydrogen phosphate $(K D P)$ crystals and KDP doped with L-alanine have been grown by slow evaporation technique at room temperature. Grown crystals have been characterized using powder X-ray diffraction, $(X R D)$, Energy Dispersive X-ray spectroscopy (EDX) and Fourier Transform Infrared spectroscopy (FTIR). The presence of L-alanine into pure KDP crystal was confirmed by FTIR and EDX spectra. Crystal structure has been studied by XRD. Pure KDP and L-alanine doped KDP crystals both possessed tetragonal structure. The transparency is found to increase with the increase of doping concentrations of the grown crystals as observed by UV-Vis spectra. A.C. electrical conductivity of grown crystals along the growth axis was carried out at various temperatures ranging from $35^{\circ} \mathrm{C}$ $400{ }^{\circ} \mathrm{C}$. Dielectric constant and dielectric losses are measured as a function of temperature and this study reveals the contribution of space charge polarization. Crystal defects and surface morphology are studied by dissolution solvent technique and reveals the step growth mechanism for both pure and doped crystals.
\end{abstract}

Keywords: Amino Acid, KDP, Solution Growth, FT-IR, Electrical Conductivity, Etch Pits

\section{Introduction}

The demand for high quality large size KDP single crystal increases due to its application as frequency conversion crystal in inertial confinement fusion [1,2]. KDP belongs to scalenohedral (twelve faced) class of tetragonal crystal system [3]. With the aim of improving the second harmonic generation (SHG) efficiency of KDP, researchers have attempted to modify KDP crystals by doping different types of impurities. The non linear optical (NLO) and other properties of the crystal have been improved by doping of organic impurities [4-9]. KDP doped with amino acids like L-glutamine acid, L-gistidine, and L-valine was reported [10]. Kumaresan et al. [11] has reported the thermal dielectric properties of amino acids such as L-glutamic acid, L-histidine and L-valine doped KDP crystals. They found improved NLO properties of the KDP crystal and modifications in the structural, optical, mechanical, and electrical properties, too. Parikh [12] has reported the SHG efficiency of L-arginine doped KDP crystal. Kumaresan et al. [13] has also reported the effect of metal ion and amino acid doping on the optical properties of KDP crystal. Muley et al. [5] has studied thermal, NLO properties of KDP crystal doped with L-arginine and L-alanine. Suresh Kumar and Rajendrababu [6] studied the effects of L-arginine, L-histidine and glycine on the growth of KDP single crystals and observed that addition of amino acid enhances transparency, thermal stability and NLO efficiency of KDP crystals.

Amino acid family crystals are playing an important role in the field of non-linear optical organic molecular crystal. Among them L-alanine (LA) with chemical formula $\left(\mathrm{CH}_{3}-\mathrm{CH}-\mathrm{NH}_{2}-\mathrm{COOH}\right)$ is the smallest, naturally occurring chiral amino acid with a non-reactive hydrophobic methyl group $\left(-\mathrm{CH}_{3}\right)$ as a side chain. LA has the zwitterionic form ( ${ }^{+} \mathrm{NH}_{3}-\mathrm{C}_{2} \mathrm{H}_{4}$ - $\left.\mathrm{COO}-\right)$ both in crystal and in aqueous solution over a wide range of $\mathrm{pH}$, which favors crystal hardness for device application [14]. It belongs to the orthorhombic crystal system and the unit cell parameters are; $\mathrm{a}=6.320 \AA, \mathrm{b}=12.343 \AA, \mathrm{c}=5.784 \AA$, $\alpha=\beta=\gamma=90^{\circ}$. Recently, several new complexes incorporating the amino acid L-alanine have been crystallized 
and their structural, optical and thermal properties have also been investigated [15-18]. The growth of pure L-alanine crystals was reported [19] and found higher damage threshold than Potassium dihydrogen phosphate (KDP).

In this paper an attempt has been made to grow large size optically transparent L-alanine doped KDP crystals by slow evaporation solution growth technique and to see the effects of L-alanine into the pure KDP crystals. In order to improve their optical properties for optoelectronics applications, L-alanine was added to $0.3,0.5,0.7$ and $1.0 \mathrm{~mol} \%$ in pure KDP. The grown crystals were characterized by FT-IR, EDX, XRD, A.C. electrical conductivity, dielectric constant, and dielectric loss, etch pits and compared all these results with pure KDP crystal.

\section{Experimental}

\subsection{Solubility Study}

Solubility of the pure KDP and LA doped KDP in double distilled water was determined gravimetrically in the temperature range $30^{\circ} \mathrm{C}-50^{\circ} \mathrm{C}$ in steps of $5^{\circ} \mathrm{C}$ using a constant temperature bath of accuracy $\pm 0.01^{\circ} \mathrm{C} .500 \mathrm{~mL}$ of the saturated solution of pure KDP salt was prepared gravimetrically at $30^{\circ} \mathrm{C}$. This solution was stirred well for six hours constantly using magnetic stirrer and then filtered using Whatman filter paper. This solution was taken in five different beakers of $100 \mathrm{~mL}$ and L-alanine was added to each of four beakers as $0.3 \mathrm{~mol} \%, 0.5$ $\mathrm{mol} \%, 0.7 \mathrm{~mol} \%$ and $1 \mathrm{~mol} \%$. After making supersaturated solution of L-alanine doped $\mathrm{KDP}, 5 \mathrm{~mL}$ of the solution was pipetted out and poured into a $10 \mathrm{~mL}$ beaker of known weight. This solvent was completely evaporated by warming the solution at $50^{\circ} \mathrm{C}$. The amount of the salt present in $5 \mathrm{~mL}$ of the solution was measured by subtracting the empty beaker's weight. From this the amount of the salt present in $100 \mathrm{~mL}$ of the solution was found out. In the same way, the amount of the salt dissolved in $100 \mathrm{~mL}$ at $35^{\circ} \mathrm{C}, 40^{\circ} \mathrm{C}, 45^{\circ} \mathrm{C}$ and $50^{\circ} \mathrm{C}$ was determined. Figure 1 shows the solubility of pure KDP and LA doped KDP salt. It is observed from the solubility graph that the solubility of pure and doped KDP in water increases as the temperature increases and decreases with doping concentration increases. From this solubility data, it can be stated that the KDP material has positive temperature coefficient.

\subsection{Crystal Growth}

The pure KDP (AR grade) and L-alanine (AR grade chemical from SIGMA) doped KDP crystals were grown using a good quality seed crystal at room temperature by solvent evaporation method. For the preparation of seed crystals, saturated solution of KDP was prepared first and then kept in a petri dish covered with a perforated polyethylene and allowed to grow seed crystals within $4-5$ days. The $\mathrm{pH}$ of the different concentration of L-alanine doped KDP solution was ranged from 4.40 to 4.90 . The purity of the crystals was improved by successive recrystallization process. The growth period takes $25-30$ days for bigger size. The grown crystals were found color-less and transparent. Figure 2 shows the photographs of pure and doped KDP crystals.

\subsection{Characterization}

The pure KDP and L-alanine doped KDP crystals were subjected to investigate the structural, optical, electrical and etching properties, etc. In order to confirm the presence of functional groups in the crystal lattice, FT-IR spectrum was recorded by $\mathrm{KBr}$ pellet technique using a Shimadzu FT-IR-8900 spectrometer in the wave number range $400-4000 \mathrm{~cm}^{-1}$. In order to confirm the presence of the elements of the compound of L-alanine into KDP crystals were studied by EDX attached with JEOL-6360 Scanning Electron Microscope. Powder X-ray diffraction pattern was recorded using a Philips X pert PRO X-ray

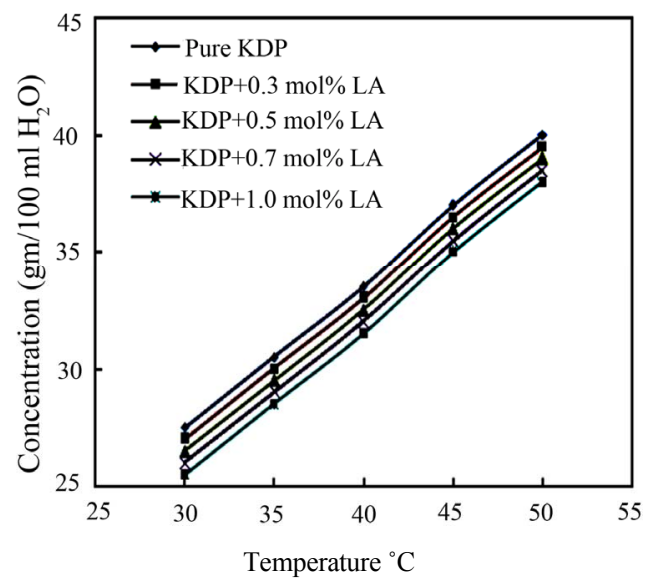

Figure 1. Solubility curve of pure and L-alanine doped KDP.

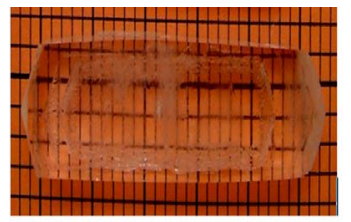

Pure KDP

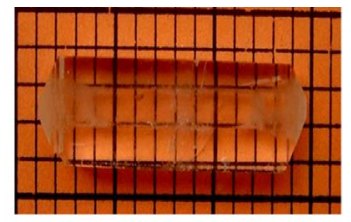

$\mathrm{KDP}+0.5 \mathrm{~mol} \% \mathrm{LA}$

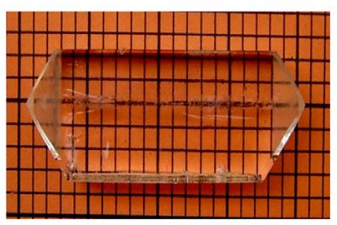

$\mathrm{KDP}+1.0 \mathrm{~mol} \% \mathrm{LA}$

Figure 2. Photographs of as grown crystals. 
diffractometer with $\mathrm{CuK} \alpha(\lambda=1.5418 \AA)$ radiation. The lattice parameters were calculated for pure KDP and doped (0.3, 0.5, 0.7 and 1.0 mole\% L-alanine) KDP crystals using XRD data. The optical properties of the grown crystal were studied by the transmission spectra using Shimadzu UV-1601 visible spectrometer in the wavelength region from 200 to $1100 \mathrm{~nm}$. The a.c. conductivity measurements were carried out along the growth axis $\mathrm{c}$ at various temperatures ranging from $35^{\circ} \mathrm{C}$ to $140^{\circ} \mathrm{C}$. The field is applied to perpendicular to c-axis. The dielectric properties were studied by using Agilent 4274A LCR meter. Dislocation, surface defects and morphology were characterized by chemical etching followed by etch pit examination using optical microscope, SWIFTMASTER II (SWIFT) Tokyo, Japan.

\section{Results and Discussion}

\subsection{FT-IR Spectroscopy}

Pure, L-arginine and L-alanine with KDP crystals were studied by FT-IR by Muley et al. [5]. The authors confirmed the interaction between KDP and organic amino acid by additional peaks corresponds to the functional groups of L-arginine and L-alanine. In this paper the FTIR spectra of pure KDP and L-alanine doped KDP crystals are shown in Figure 3. In the FT-IR spectrum of pure KDP, the O-H stretching vibration of water happened at $3239 \mathrm{~cm}^{-1}$, P-O-H stretching at $2249 \mathrm{~cm}^{-1}$, $\mathrm{HO}-\mathrm{P}-\mathrm{OH}$ bending at $749 \mathrm{~cm}^{-1}$, P-OH deformation or $\mathrm{K}-\mathrm{O}$ stretching at $582 \mathrm{~cm}^{-1}$ and $\mathrm{PO}_{4}$ stretching at 416 $\mathrm{cm}^{-1}$. In the FTIR spectrum of $1.0 \mathrm{~mol} \% \mathrm{~L}$-alanine doped $\mathrm{KDP}$ crystal, C-H stretching at $2812 \mathrm{~cm}^{-1}$ and $\mathrm{CH}_{2}$ bending at $1237 \mathrm{~cm}^{-1}$ have been observed. Table 1 shows the vibrational frequencies corresponding to the band assignments of pure and doped KDP crystals. The following vibration assignments showed the hydrogen bonding extends throughout the L-alanine doped KDP molecules. These hydrogen bonding results in the modification of stretching frequencies of $\mathrm{O}-\mathrm{H}$ group of $\mathrm{KDP}$ and the carboxyl group of L-alanine molecules. This confirms the presence of L-alanine into pure KDP crystal.

\subsection{Energy Dispersive $X$-ray Analysis}

In order to confirm the presence of the elements of L-alanine into pure KDP crystals, the sample of grown crystals were subjected to Energy Dispersive X-ray analysis. Figure 4 shows the EDX result of pure KDP and L-alanine doped KDP crystals. Elements are identified and presented as atomic $\%$.

\subsection{Powder X-ray Diffraction}

The powder XRD study was conducted to verify the sin- gle phase nature of the samples. Figure 5 shows the powder XRD patterns of pure and L-alanine doped KDP crystals. "X" PERT HIGHSCORE X-ray software was used for analysis of powder XRD patterns. Well defined Bragg peaks are obtained at specific $2 \theta$ angles indicating that crystals are ordered. The ' $d$ ' spacing and hkl values for prominent peaks in the spectrum were identified and compared with ICDD (International Centre for Diffraction Data). Using tetragonal crystallographic equation, lattice parameter values are calculated and listed in Table 2. This suggests that the crystals retain almost the single phase structure and exhibit very slight variation in the unit cell parameters on doping of L-alanine. The variation in the intensities of various diffraction patterns on changing the concentration of doping was observed.

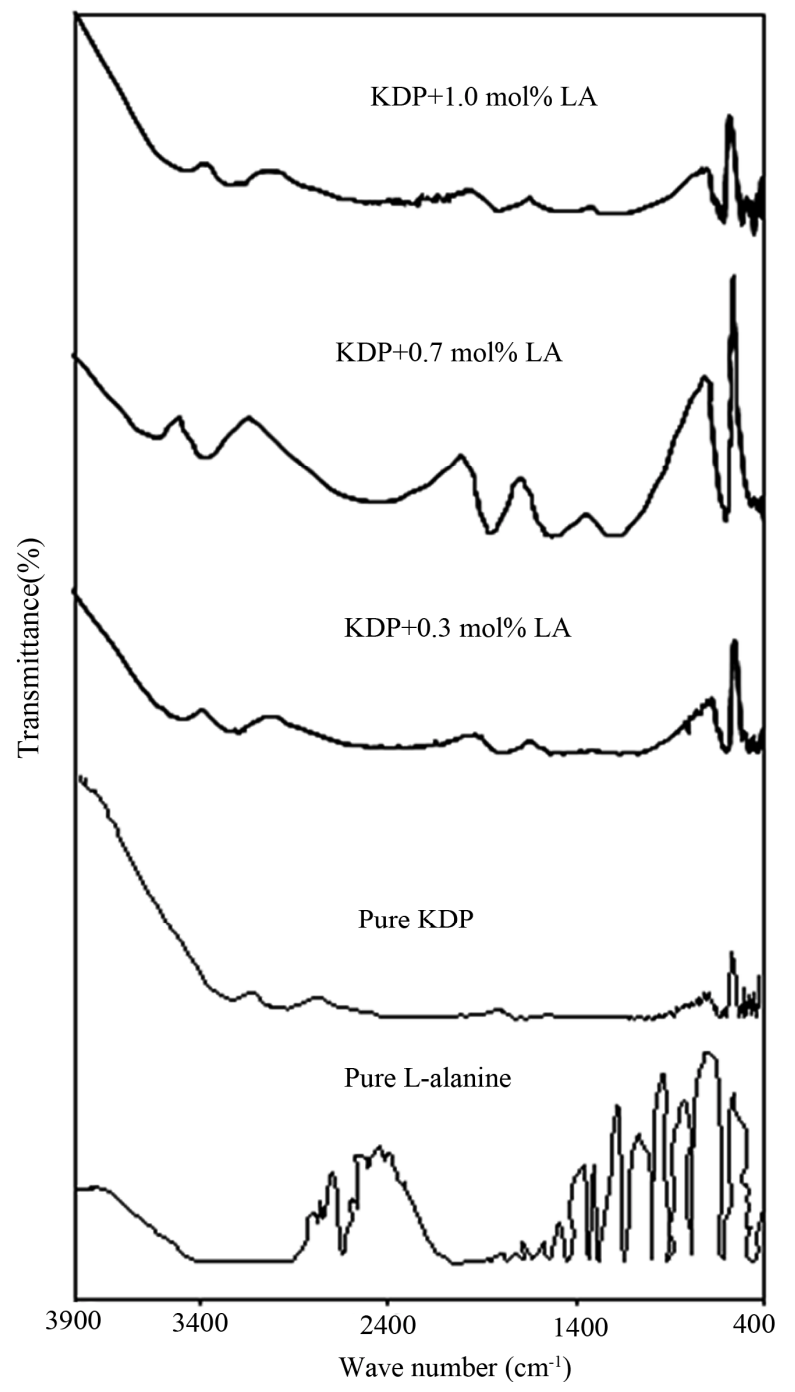

Figure 3. FTIR spectra of as grown crystals. 
Table 1. Vibrational frequencies for pure and doped KDP crystals.

\begin{tabular}{|c|c|c|c|c|}
\hline \multicolumn{5}{|c|}{ L-alanine doped KDP } \\
\hline Pure KDP & $0.3 \mathrm{~mol} \%$ & $0.7 \mathrm{~mol} \%$ & $1 \mathrm{~mol} \%$ & Assignments \\
\hline $\mathrm{cm}^{-1}$ & $\mathrm{~cm}^{-1}$ & $\mathrm{~cm}^{-1}$ & $\mathrm{~cm}^{-1}$ & \\
\hline 3239 & 3226 & 3232 & 3218 & O-H stretching, H-bonded \\
\hline 3072 & 3115 & 3156 & 3121 & O-H stretching \\
\hline 2929 & 2958 & 2910 & 2942 & O-H stretching \\
\hline 2819 & 2892 & 2871 & 2840 & Intermolecular $\mathrm{H}$-bonded ${ }^{-} \mathrm{OH}$ stretching \\
\hline- & 2841 & 2824 & 2812 & $\mathrm{C}-\mathrm{H}$ stretching \\
\hline 2525 & 2548 & 2539 & 2575 & O-H stretching \\
\hline 2249 & 2285 & 2236 & 2285 & P-O-H symmetric stretching \\
\hline 1676 & 1674 & 1625 & 1648 & O-P-OH symmetric stretching \\
\hline 1463 & 1384 & 1369 & 1373 & $\mathrm{O}-\mathrm{H}$ stretching \\
\hline 1230 & 1233 & 1232 & 1237 & $\mathrm{CH}_{2}$ bending, $\mathrm{P}=\mathrm{O}$ symmetric stretching \\
\hline 1142 & 1076 & 1100 & 1060 & P-O-H symmetric stretching \\
\hline 866 & 938 & 957 & 949 & $\mathrm{O}=\mathrm{P}-\mathrm{OH}$ bending \\
\hline 749 & 767 & 72 & 652 & HO-P-OHbending \\
\hline 582 & 574 & 570 & 587 & $\mathrm{P}-\mathrm{OH}$ deformation/K-O stretching \\
\hline 416 & 455 & 419 & 445 & $\mathrm{PO}_{4}$ stretching \\
\hline
\end{tabular}

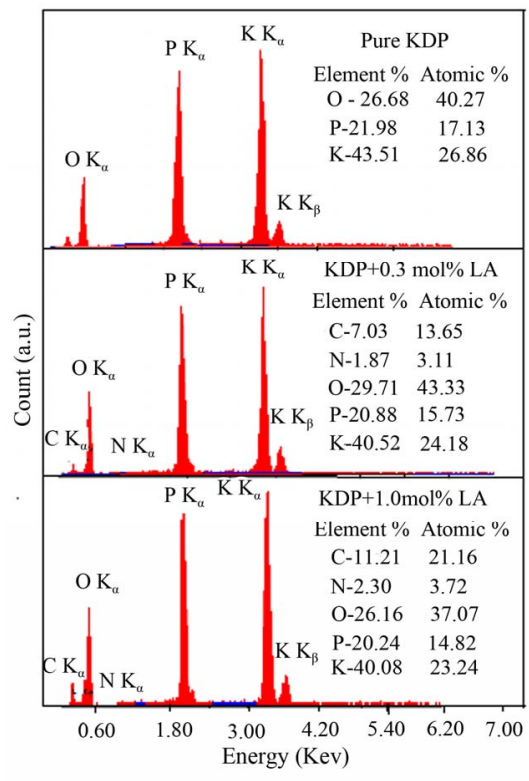

Figure 4. EDX spectra of pure and L-alanine doped KDP crystals.

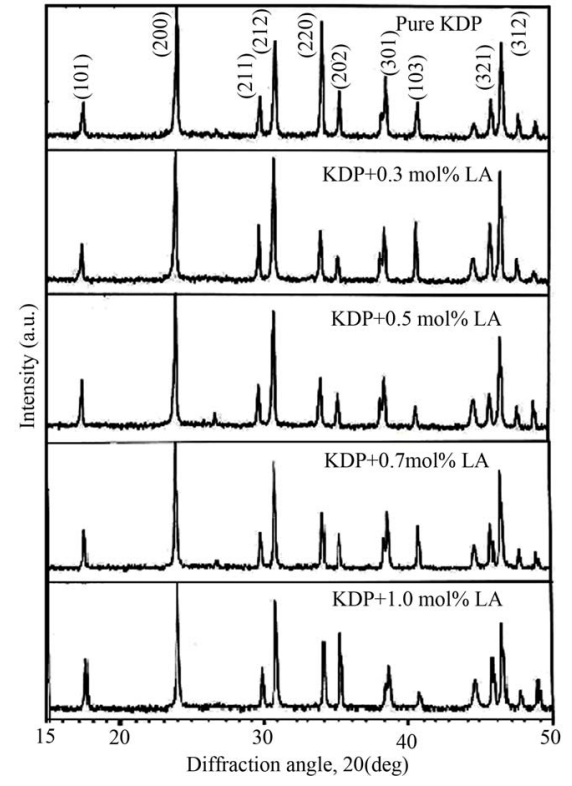

Figure 5. Powder XRD pattern of pure and L-alanine doped KDP crystals.

Table 2. Lattice parameters and optical transmission for pure and doped KDP crystals.

\begin{tabular}{ccccc}
\hline Sample & Crystal system & Lattice parameters a $=\mathrm{b}, \mathrm{c}(\AA)$ & Cell volume $\left(\AA^{3}\right)$ & Optical transmission $(\%)$ \\
\hline Pure KDP & Tetragonal & $7.455,6.975$ & 387.649 & 85 \\
KDP+0.3 mol\% LA & Tetragonal & $7.426,6.981$ & 384.981 & 87 \\
KDP+0.5 mol\% LA & Tetragonal & $7.422,6.993$ & 385.216 & 90 \\
KDP+0.7 mol\% LA & Tetragonal & $7.427,6.979$ & 384.989 & 92 \\
KDP+ 1.0 mol\% LA & Tetragonal & $7.423,6.995$ & 385.415 & 97 \\
\hline
\end{tabular}




\subsection{UV-Vis Study}

The UV-Vis optical transmission spectra of pure and L-alanine doped KDP crystals are shown in Figure 6. It is clear from the figure that the percentage of optical transmission increases with the increase of concentration of L-alanine in KDP crystals. All of them have sufficient transmission in the entire visible and near IR region. The percentage of optical transmission data are tabulated in Table 2. The UV transparency cut-off limits decreases with the doping concentration. Similar results have been obtained in the case of L-alanine doped KDP [8]. Absorption in the near ultraviolet region arises from electronic transitions associated within the sample. Hence, it could be concluded that the L-alanine doping play a key role in improving the optical quality of KDP crystals. This is the most desirable property of materials possessing NLO activity.

\subsection{A.C. Conductivity and Dielectric Studies}

The a.c. conductivity $\left(\sigma_{\mathrm{ac}}\right)$, dielectric constant $\left(\varepsilon_{\mathrm{r}}\right)$ and dielectric $\operatorname{loss}(\tan \delta)$ of pure KDP and L-alanine doped KDP crystals were carried out at different temperatures ranging from $35^{\circ} \mathrm{C}$ to $140^{\circ} \mathrm{C}$ at a particular frequency $1 \mathrm{kHz}$ by LCR meter. The samples were cut and polished using wet cloth polishing sheet. The sample dimensions were $8 \mathrm{~mm} \times$ $6 \mathrm{~mm}$ surfaces area and $2 \mathrm{~mm}$ thickness. The sample was electrode on either side with silver paste to make it behaves like parallel plate capacitor. Silver paste electrodes on opposite sides ensure good electrical contacts. The resistance, capacitance, and dissipation factor values were directly measured from LCR meter. From the values of capacitance and dissipation factor, the dielectric constant and dielectric loss of the samples were calculated. The dielectric constant $\left(\varepsilon_{\mathrm{r}}\right)$ of the all KDP crystals were calculated through the capacitance by the fundamental equation, $\varepsilon_{\mathrm{r}}=\mathrm{Ct} / 0.0885 \mathrm{~A}$, where $\mathrm{C}$ is the capacitance, $\mathrm{t}$ is the thickness and $\mathrm{A}$ is the area of the samples. The dielectric loss $(\tan \delta)$ of the samples were calculated by the relation, $\tan \delta=$ dissipation factor $\times \varepsilon_{\mathrm{r}}$. The a.c. conductivity $\left(\sigma_{\mathrm{ac}}\right)$ has been calculated using the expression: $\sigma_{\mathrm{ac}}=2 \pi \mathrm{fCt} / \mathrm{A}$, where $\mathrm{f}$ is the frequency of applied field. The a.c. conductivity, dielectric constant and dielectric loss at different temperatures of pure and L-alanine doped KDP crystals have been shown in Figures 7-9. The a.c. conductivity is found to increase with the increase in temperature but decreases with L-alanine concentrations. Electrical conductivity of the KDP group crystals is determined by the proton transport within the framework of hydrogen bonds [20]. The mechanism can be considered here is identical to the conductivity mechanism in ice also containing hydrogen bonds. It is assumed that the conductivity of ice is determined by the simultaneous presence of positive and negative ions and orientational

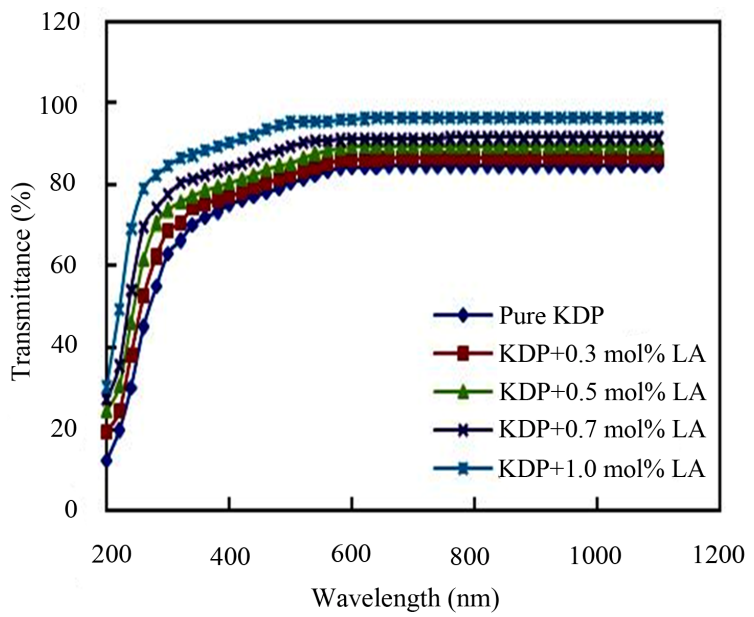

Figure 6. Optical transmission of pure and L-alanine doped KDP crystals.

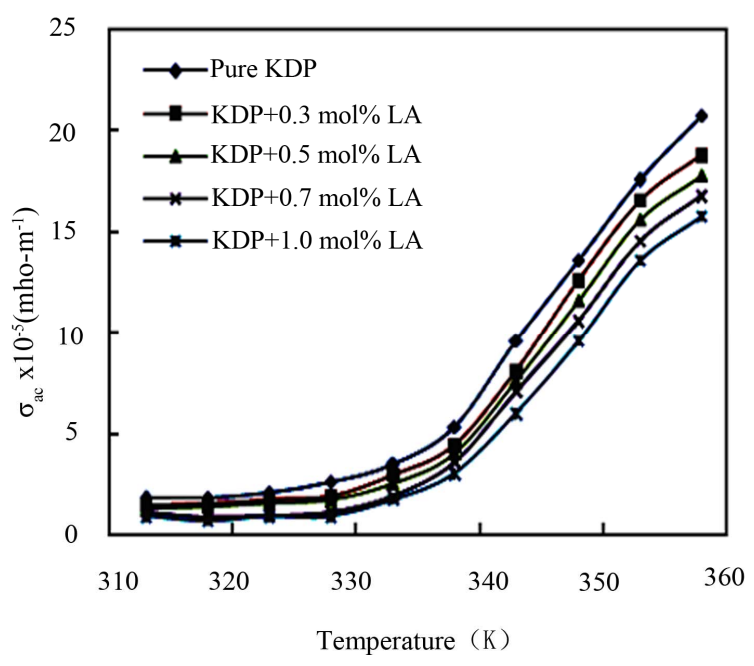

Figure 7. A.C. conductivity vs. temperature.

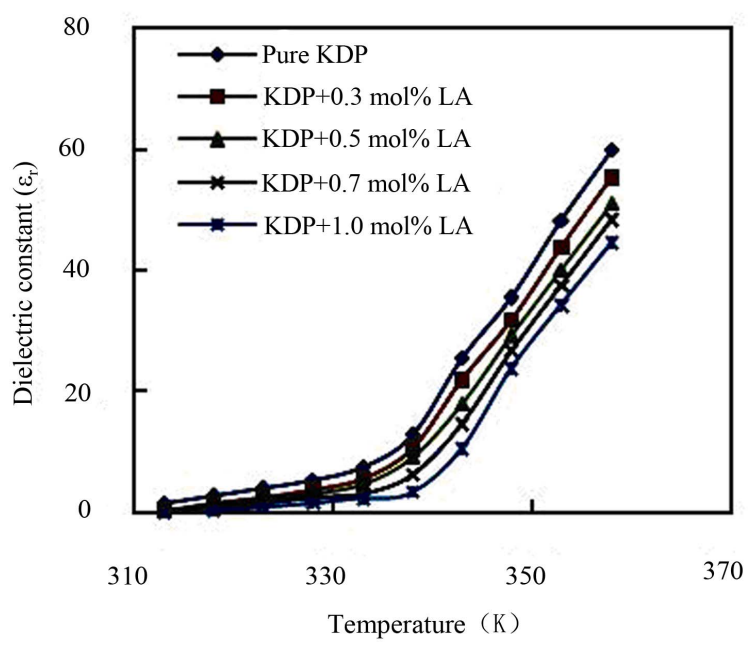

Figure 8. Plot of dielectric constant vs. temperature. 


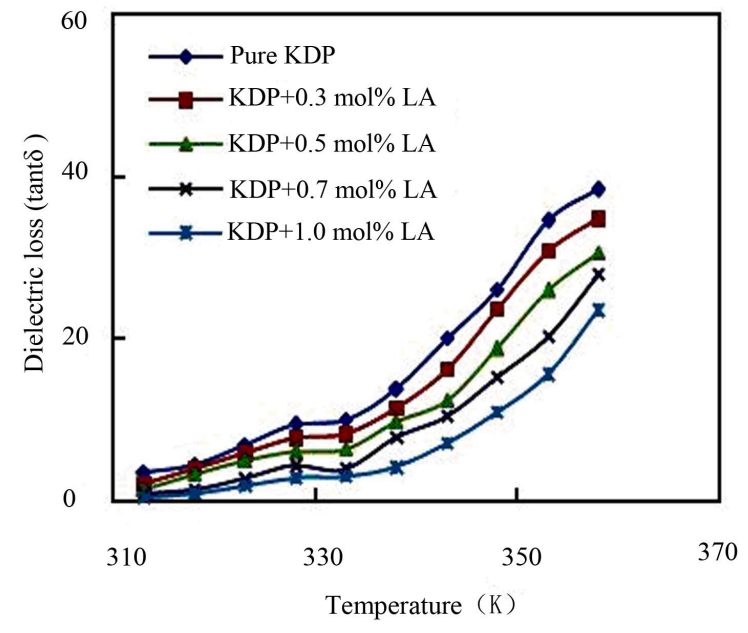

Figure 9. Plot of dielectric loss vs. temperature.

defects-vacant hydrogen bonds (L-defects) and doubly occupied hydrogen bonds (D-defects). Other possible defects are vacancies and defect associates. The experimental data and especially the character of the temperature dependence of conductivity allow us to state that the conductivity of KDP crystals is determined by both thermally generated L-defects and foreign impurities incorporated into the lattice and generating L-defects there [20]. As the conduction in KDP is protonic and mainly due to the anion $\left(\mathrm{H}_{2} \mathrm{PO}_{4}\right)^{-}$and not the cation $\left(\mathrm{K}^{+}\right)$for $\mathrm{KDP}$, the additional hydrogen bonds created may reduce the L-defects and consequently obstruct the movement of protons. This may be the reason for the decrease in conductivity value with the increase in impurity concentration. The nature of variations of dielectric constant with temperature indicates the contribution of ionic, electronic, orientational and space charge polarization. Generally the low value of dielectric loss indicates that the sample possesses good crystalline quality with fewer defects. The lower value of dielectric constant is a suitable parameter for the enhancement of second harmonic generation (SHG) signals.

\subsection{Etching Studies}

Etching is the selective dissolution of the crystal which reveals the crystal symmetry and lattice defects [21]. Patterns observed on surface like spirals, hillocks and step pattern, etc yield considerable information on the growth process and growth mechanism of the crystal. When a surface is etched, well defined etch patterns are produced at the dislocation sites. The chemical etching studies were carried out on the as grown crystals of pure $\mathrm{KDP}$ and L-alanine doped KDP crystals to investigate the distribution of structural defects in the grown crystals. The surfaces of samples were polished and then etched in the etching solution (water) at room temperature for $10 \mathrm{~s}$. Then soaked with a filter paper and examined under an optical microscope in reflection mode. Figures $\mathbf{1 0}$ and $\mathbf{1 1}$ illustrate the typical etch patterns observed on the (001) plane of the pure KDP and L-alanine doped KDP crystals. When the crystals were etched in water, the triangular type etch pits were observed and the etch-pit density (EPD) for pure KDP crystal was found $2.5 \times 10^{2} \mathrm{~cm}^{-2}$ and for L-alanine doped KDP crystal was $14.28 \times 10^{2}$ $\mathrm{cm}^{-2}$. Usually, these etching pits are considered as outcrop of dislocation lines. The shape of these etching pits is determined by the lattice structure and symmetry [22]. This is also evident from the fact that the bottom of the crystal is flat. It means that the crystals are grown from the bottom of the beaker/container and not in the middle of the solution. The presence of dislocations strongly influences many of the properties of crystals. The generation of dislocations is strongly correlated with the formation of inclusions in the crystals. The formation of inclusions destroys the normal build of lattices, which results in stress and lattice mismatch in crystal. In order to relax the stress and adjust the lattice mismatch, lots of dislocations were produced. That's why so many disloca-

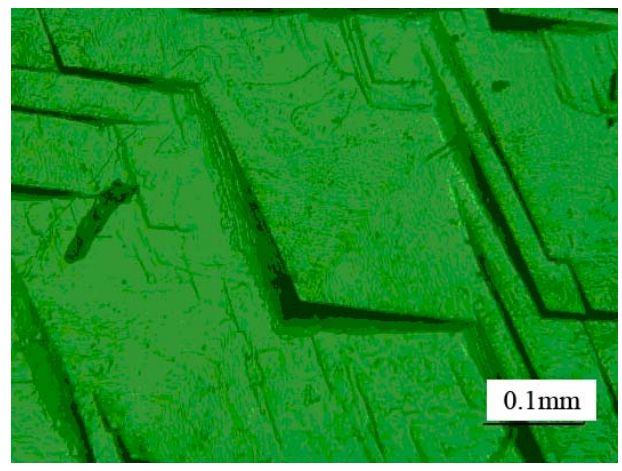

Figure 10. Etch pit pattern of (001) plane of pure KDP crystal.

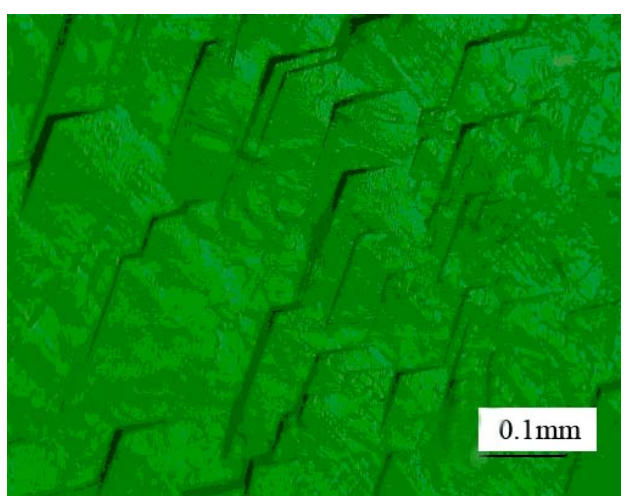

Figure 11. Etch pit pattern of (001) plane of $1.0 \mathrm{~mole} \%$ L-alanine doped KDP crystal. 
tion etching pits are observed in doped KDP crystal.

\section{Conclusions}

The effect of amino acid (L-alanine) impurity on the growth of KDP from supersaturated solutions has beeninvestigated experimentally by measuring optical transmission, functional groups, A.C. electrical conductivity and dielectrics properties. The presence of amino acid impurity in KDP solution was found to increase the optical transmission, electrical conductivity with temperature. This phenomenon may be attributed due to zwitterionic nature of L-alanine molecule $\left({ }^{+} \mathrm{NH}_{3}-\mathrm{C}_{2} \mathrm{H}_{4}-\mathrm{COO}-\right)$. The growth process is studied by dissolution solvent technique and reveals the step growth mechanism for both pure and doped crystals. The enhancement of optical transmission of L-alanine doped KDP crystals highlights their prospects of application as NLO materials.

\section{Acknowledgements}

The authors are thankful to Dr. Dilip Kumar Saha, C.S. O., for XRD measurements and Mr. Harinarayan Das, S.O. and Md. Al-Mamun, S.O., Atomic Energy Centre, Dhaka, Bangladesh, for EDX measurements.

\section{REFERENCES}

[1] X. Sun, X. Xu, Z. Gao, Y. Fu, S. Wang, H. Zeng and Y. $\mathrm{Li}$, "Effect of EDTA on the Light Scatter in KDP Crystals," Journal of Crystal Growth, Vol. 217, 2000, pp. 404-409.

[2] N. Zaitseva, L. Carman, and I. Smolsky, "Habit Control during Rapid Growth of KDP and DKDP Crystals," Journal of Crystal Growth, Vol. 241, No. 3, 2002, pp. 363373. doi:10.1016/S0022-0248(02)01244-7

[3] R. W. G. Wyckoff, "Crystal Structure," 2nd Edition, Interscience, New York, 1960.

[4] J. Podder, "The Study of Impurities Effect on the Growth and Nucleation Kinetics of Potassium Dihydrogen Phosphate," Journal of Crystal Growth, Vol. 237-239, 2002, pp. 70-75. doi:10.1016/S0022-0248(01)01854-1

[5] G. G. Muley, M. N. Rode and B. H. Pawar, "FT-IR, Thermal and NLO Studies on Amino Acid (L-Arginine and L-Alanine) Doped KDP Crystals," Acta Physica Polonica A, Vol. 116, 2009, pp. 1033-1038.

[6] B. Suresh Kumar and K. Rajendra Babu, "Effect of L-Arginine, L-Histidine and Glycine on the Growth of KDP Single Crystals and Their Characterization," Indian Journal of Pure and Applied Physics, Vol. 46, No. 2, 2008, pp. 123-126.

[7] S. Gunasekaran and G. R. Ramkumaar, "Analysis on Suitability of Pure and $\alpha$-Histidine Doped KDP Crystals in High Speed Applications," Indian Journal of Physics, Vol. 83, No. 11, 2009, pp. 1549-1555. doi:10.1007/s12648-009-0138-4
[8] K. D. Parikh, D. J. Dave, B. B. Parekh and M. J. Joshi, "Growth and Characterization of L-Alanine Doped KDP Crystals," Crystal Research and Technology, Vol. 45, No. 6, 2010, pp. 603-610. doi:10.1002/crat.201000019

[9] M. Priya, C. M. Padma, T. H. Freeda, C. Mahadevan and C. Balasingh, "Electrical Conductivity Measurements on Gel Grown KDP Crystals Added with Urea and Thiourea," Bulletin of Material Science, Vol. 24, No. 5, 2001, pp. 511-514. doi:10.1007/BF02706723

[10] P. Kumaresan, S. Moorthy Babu and P. M. Anbarasan "Influence of Dopants (L-Glutamic Acid, L-Histidine and L-Valine) on the Performance of KDP Crystals," 4th DAE-BRNS Laser Symposium, Vol. 4, 2005, pp. 521-522.

[11] P. Kumaresan, B. S. Moorthy Babu and P. M. Anbarasan, "Thermal Dielectric Studies on Pure and Amino Acid (L-Glutamine, L-Histadine, L-Valine) Doped KDP Single Crystals," Optical Materials, Vol. 30, No. 9, 2001-1368. doi:10.1016/j.optmat.2007.07.002

[12] K. D. Parikh, D. J. Dave, B. B. Parekh and M. J. Joshi, "Thermal, FT-IR and SHG Efficiency Studies of L-Arginine Doped KDP Crystals," Bulletin of Material Science, Vol. 30, No. 2, 2007, pp. 105-112. doi:10.1007/s12034-007-0019-4

[13] P. Kumaresan, B. S. Moorthy Babu and P. M. Anbarasan, "Effect of Metal Ion and Amino Acid Doping on the Optical Performance of KDP Single Crystals," Journal of Optoelectronics and Advanced Materials, Vol. 1, No. 2, 2007, pp. 65-69.

[14] A. Anne Assencia and C. Mahadevan, "D.C. Electrical Conductivity Measurements on ADP Single Crystals Added with Simple Organic Compounds," Bulletin of Material Science, Vol. 28, No. 5, 2005, pp. 415-418. doi:10.1007/BF02711229

[15] J. D. Bernal, "The Crystal Structure of the Natural Amino Acids and Related Compounds," Zeitschrift für Kristallographie, Vol. 78, 1931, pp. 363-369.

[16] H. J. Simpson Jr. and R. E. Marsh, "The Crystal Structure of L-Alanine," Acta Crystallographica, Vol. 20, 1966, pp. 550-555. doi:10.1107/S0365110X66001221

[17] R. Destro, R. E. Marsh and R. Bianchi, "A Low Temperature (23K) Study of L-alanine," The Journal of Physical Chemistry, Vol. 92, 1988, pp. 966-973. doi: $10.1021 / \mathrm{j} 100315 \mathrm{a} 022$

[18] L. Misoguti, A. T. Varela, F. D. Nunes, V. S. Bagnato, F. E. A. Melo, J. Mendes Filho and S. C. Zilio, "Optical Properties of L-Alanine Organic Crystals," Optical Materials, Vol. 6, No. 3, 1996, pp. 147-152. doi:10.1016/0925-3467(96)00032-8

[19] N. Vijayan, S. Rajasekaran, G. Bhagavannarayana, R. Ramesh Babu, R. Gopalakrishnan, M. Palanichamy and P. Ramasamy, "Growth and Characterization of Nonlinear Optical Amino Acid Single Crystal: L-Alanine," Crystal Growth \& Design, Vol. 6, No. 11, 2006, pp. 2441-2445. doi: $10.1021 / \operatorname{cg} 049594 y$ 8, pp. 136

[20] L. B. Harris and G. J. Vella, "Conductivity of Single Crystals of Potassium Dihydrogen Phosphate," Journal of Applied Physics, Vol. 37, No. 11, 1967, pp. 4294-4294. 
[21] K. Sangwal and R. B. Heimann, "Etching of Crystals: Theory, Experiments and Applications," North Holland, Amsterdam, 1987.

[22] K. Sangwal and I. Owczarek, "On the Formation of Etch
Grooves at Impurity Striations and Growth Sector Boundaries in Crystals Grown from Solutions," Journal of Crystal Growth, Vol. 129, No. 3-4, 1993, pp. 640-652. doi:10.1016/0022-0248(93)90500-V 